\title{
Structural and magnetic properties of mechanochemically synthesized nanosized yttrium titanate
}

\author{
Tanja Barudžija ${ }^{1}$, Alexey A. Gusev ${ }^{2}$, Dragana Jugović ${ }^{3}$, Milena Marinović-Cincović ${ }^{1}$, Miroslav Dramićanin ${ }^{1}$, \\ Miodrag Zdujić ${ }^{3}$, Čedomir Jovalekić ${ }^{4}$, Miodrag Mitrić ${ }^{1}$ \\ ${ }^{1}$ University of Belgrade, Institute for Nuclear Sciences "Vinča", Belgrade, Serbia \\ ${ }^{2}$ Institute of Solid State Chemistry and Mechanochemistry, The Siberian Branch of the Russian Academy of Sciences, \\ Novosibirsk, Russia \\ ${ }^{3}$ Institute of Technical Sciences of the Serbian Academy of Sciences and Arts, Belgrade, Serbia \\ ${ }^{4}$ University of Belgrade, Institute for Multidisciplinary Research, Belgrade, Serbia
}

\begin{abstract}
Nanosized perovskite $\mathrm{YTiO}_{3}$ with mean crystallite size of $18 \mathrm{~nm}$ was synthesized for the first time by mechanochemical treatment. The mechanochemical solid state reaction between commercial $\mathrm{Y}_{2} \mathrm{O}_{3}$ powder and mechanochemically synthesized TiO powder in molar ratio $0.5: 1$ was performed over $3 \mathrm{~h}$ in a high-energy planetary ball mill in argon atmosphere. Heating in vacuum at $1150{ }^{\circ} \mathrm{C}$ for $12 \mathrm{~h}$ transforms nanosized $\mathrm{YTiO}_{3}$ to a wellcrystallized single-phase perovskite $\mathrm{YTiO}_{3}$. Both samples were characterized by X-ray diffraction (XRD) and thermogravimetric (TGA/DTA) analyses, as well as superconducting quantum interference device magnetometer (SQUID) measurements.
\end{abstract}

Keywords: yttrium titanate; mechanochemical synthesis; nanomaterials; structural properties; magnetic properties.

\section{SCIENTIFIC PAPER}

UDC 544:661.893

Hem. Ind. 66 (3) 309-315 (2012)

doi: 10.2298/HEMIND111103103B

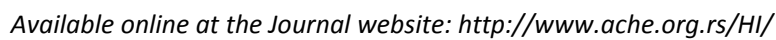

Yttrium titanate $\left(\mathrm{YTiO}_{3}\right)$ is a system exhibiting the Mott-Hubbard insulating state [1]. $\mathrm{YTiO}_{3}$ is a ferromagnet with Curie temperature $T_{C} \approx 30 \mathrm{~K}$ [2]. The crystal structure of $\mathrm{YTiO}_{3}$ is pseudocubic perovskite with strong $\mathrm{GdFeO}_{3}$-type distortion, which is caused by the tilt of the $\mathrm{TiO}_{6}$ octahedra [3]. $\mathrm{GdFeO}_{3}$-type distortion plays an important role in the electronic and magnetic properties of perovskite titanates $R \mathrm{TiO}_{3}$ ( $R$ being a trivalent yttrium or rare-earth ion). The magnitude of the distortion depends on the ionic radius of the $R$ ion: upon the decrease of ionic radius in the rare-earth series the deviation of the $\mathrm{Ti}-\mathrm{O}-\mathrm{Ti}$ bond angle from $180^{\circ}$ occurs, i.e., the lattice distortion increases [3]. Besides the bond geometry changes, tilting of the $\mathrm{TiO}_{6}$ octahedra affects the one-electron bandwidth of the $3 \mathrm{~d}$ electron in a way that it gets smaller with the decrease of ionic radius [4]. With the increase of $\mathrm{GdFeO}_{3}$-type distortion the Ti magnetic order changes from $G$-type antiferromagnetic, with the magnetic moment in the $a$ direction $\left(\mathrm{LaTiO}_{3}\right)$, to ferromagnetic, with the magnetic moment in the $c$ direction $\left(\mathrm{YTiO}_{3}\right)[5,6]$. Variation of the magnetic properties appears to be a continuous function of the distortion, as demonstrated by the study of the magnetic properties in $R \mathrm{TiO}_{3}$ with varying $R$ species [7], as well as in the solid solutions $\mathrm{La}_{x} \mathrm{Y}_{1-x} \mathrm{TiO}_{3}$ [8].

Correspondence: M. Mitrić, Institute for Nuclear Sciences "Vinča", P.O. Box 522, 11001 Belgrade, Serbia.

E-mail:mmitric@vinca.rs

Paper received: 3 November, 2011

Paper accepted: 5 December, 2011
Due to the low symmetry of the $R \mathrm{TiO}_{3}$ crystal structure, the $G$-type antiferromagnetic component in the $a$ direction is coupled with an A-type antiferromagnetic moment in the $b$ direction and a ferromagnetic component in the $c$ direction [9]. Thus, the change from antiferromagnetic (AFM) to ferromagnetic (FM) order of the Ti moments in the series of $R \mathrm{TiO}_{3}$ is the result of ordered moment redistribution between the three different components $\left(G_{x}, A_{y}\right.$ and $\left.F_{z}\right)$ within the same magnetic symmetry. Consequently, the change in the magnetic ordering can occur, not only by varying $R$ ionic radius, but also by any change in bond geometry caused by defects in the system (including vacancies and impurities). Since the mechanochemical synthesis is known for producing materials with plenty of structural defects, we have synthesized $\mathrm{YTiO}_{3}$ by mechanochemical treatment and carried out crystal structure and magnetic properties investigation. For the sake of comparison, the annealed $\mathrm{YTiO}_{3}$ sample, which has a well-stabilized structure, was also examined.

\section{EXPERIMENTAL}

Commercial $\mathrm{Y}_{2} \mathrm{O}_{3}$ and mechanochemically synthesized TiO [10] powders were weighed in molar ratio $0.5: 1$ to obtain $7 \mathrm{~g}$ of the powder mixture. Milling was done using a planetary ball mill Fritsch Pulverisette 7, with a pair of tungsten carbide vials of $45 \mathrm{ml}$ volume containing 144 tungsten carbide balls of $5 \mathrm{~mm}$ diameter in argon atmosphere under the same milling conditions, as previously described [10]. After the se- 
lected milling times $(10,30,60$ and $180 \mathrm{~min})$, some amount of powder was taken for X-ray diffraction measurements (Philips PW 1050 powder diffractometer with $\mathrm{Ni}$ filtered $\mathrm{CuK} \alpha$ radiation and scintillation detector) within $10-70^{\circ} 2 \theta$ range in steps of $0.05^{\circ}$, where the scanning time was $5 \mathrm{~s}$ per step. After the XRD measurements, the powder was returned into the vial in order to keep the same milling conditions. The vial had been evacuated and refilled with argon beforehand and afterwards.

The sample milled for $180 \mathrm{~min}$ was subsequently heated at $1150{ }^{\circ} \mathrm{C}$ in an evacuated and sealed quartz ampoule for $12 \mathrm{~h}$ and slowly (furnace) cooled. The XRD measurements on the annealed sample were done applying the same conditions as for all as-milled samples.

The magnetic measurements were done on both mechanochemically synthesized and annealed samples by using a Quantum Design MPMS XL-5 SQUID magnetometer. Temperature dependency of the magnetic susceptibility was investigated in the temperature range of 2-200 K, and the experimental data were corrected for temperature independent diamagnetic susceptibility using the gram ionic susceptibility values given by Selwood [11]. Field dependency of the isothermal magnetization was recorded in the magnetic fields range of $\pm 50 \mathrm{kOe}$ and at a temperature of $24 \mathrm{~K}$.

Simultaneous TGA/DTA measurements were carried out up to $900{ }^{\circ} \mathrm{C}$ in air atmosphere at the heating rate of $20{ }^{\circ} \mathrm{C} \mathrm{min}^{-1}$ using a TA SDT Model 2090 thermobalance.

\section{RESULTS AND DISCUSION}

\section{Mechanochemical synthesis and thermogravimetric analysis}

Figure 1 shows the XRD patterns of $\mathrm{Y}_{2} \mathrm{O}_{3}$ and TiO mixture in the molar ratio 0.5:1 milled for various time periods. The starting powder mixture exhibits sharp peaks of cubic $\mathrm{Y}_{2} \mathrm{O}_{3}$ and broad weak peaks of cubic mechanochemically synthesized TiO [10]. After $10 \mathrm{~min}$ of milling, all sharp peaks of $\mathrm{Y}_{2} \mathrm{O}_{3}$ have broadened due to the reduction of crystalline size and the accumulation of lattice strain. After 30 min of milling, new broad peaks of perovskite $\mathrm{YTiO}_{3}$ can be resolved, thus indicating the formation of a new phase as the result of mechanochemical reaction. Prolonged milling (180 $\mathrm{min}$ ) leads to the formation of single-phase perovskite $\mathrm{YTiO}_{3}$ (the sample phase identification was performed by inorganic crystal structure database ICSD, collection code \#8150).

It should be pointed out that the same powder mixture was also milled in air atmosphere. The XRD analysis revealed that mechanochemical reaction did not lead to the formation of $\mathrm{YTiO}_{3}$, but rather to a $\mathrm{Y}_{2} \mathrm{Ti}_{2} \mathrm{O}_{7}$ phase (results not presented). Obviously, the mechanochemical treatment induces solid-solid reaction between $\mathrm{Y}_{2} \mathrm{O}_{3}$ and $\mathrm{TiO}$, as well as gas-solid reaction with oxygen from air. On the other hand, in the case when mechanochemical treatment was carried out in argon atmosphere the oxygen could affect the reaction (so that stoichiometry $1 / 2 \mathrm{Y}_{2} \mathrm{O}_{3}+\mathrm{TiO}+\mathrm{O}_{2} \rightarrow \mathrm{YTiO}_{3}$ could be fulfilled), but possibly only when mechanochemically activated powder was exposed to the air atmosphere during the XRD measurements.

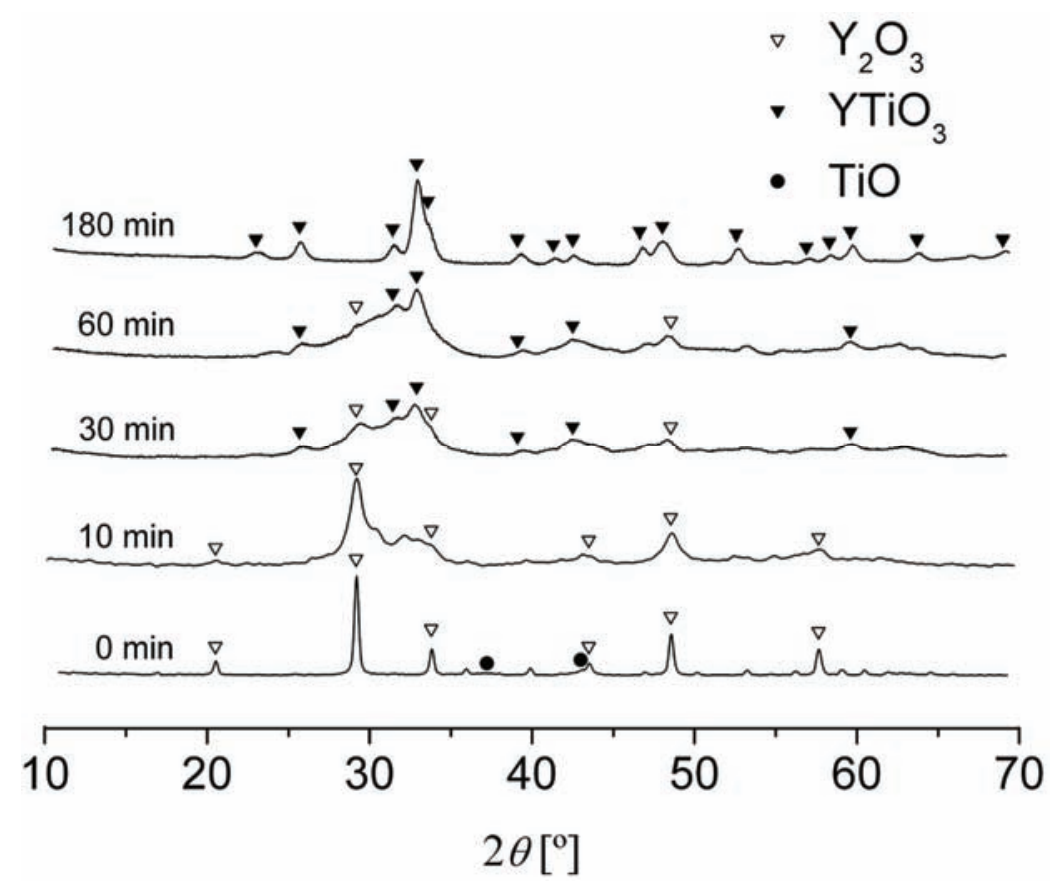

Figure 1. XRD Patterns of the mixture of $\mathrm{Y}_{2} \mathrm{O}_{3}$ and TiO powders milled for $0,10,30,60$ and 180 min. 
The annealing of mechanochemically synthesized sample at $1150{ }^{\circ} \mathrm{C}$ yielded well crystallized, singlephase perovskite $\mathrm{YTiO}_{3}$ (Figure 2).

The mean crystallite size of as-milled sample was estimated by the Scherrer formula [12], using the appropriate instrumental resolution function for $\mathrm{LaB}_{6}$ as the standard, from the diffraction peak that correspond to (111) reflection at about $2 \theta \approx 26^{\circ}$. The value of crystallite size obtained this way was $18 \mathrm{~nm}$.

The oxygen content of mechanochemically synthesized sample was assessed from the mass increase observed by TGA (Figure 3). Due to the $\mathrm{Ti}^{3+} \rightarrow \mathrm{Ti}^{4+}$ instability, $\mathrm{YTiO}_{3}$ always has an excess of oxygen compared to the exact stoichiometry formula. Based on the weight gain, the oxygen excess $\delta$ in the formula $\mathrm{YTiO}_{3+\delta}$ is estimated to be less than $\delta=0.019$. The oxidation was accompanied by DTA exothermic effects at $450{ }^{\circ} \mathrm{C}$. Above $450{ }^{\circ} \mathrm{C} \mathrm{Ti}^{3+}$ fully oxidize to $\mathrm{Ti}^{4+}$, i.e., $\mathrm{YTiO}_{3}$ oxidizes to $\mathrm{Y}_{2} \mathrm{Ti}_{2} \mathrm{O}_{7}$.

\section{Magnetic properties}

To investigate the magnetic properties of both the mechanochemically synthesized and annealed $\mathrm{YTiO}_{3}$ samples, the temperature dependency of the magnetic susceptibility was measured in the temperature range of 2-200 K (Figure 4). For both samples magnetic transition temperature, $T_{c}$, was determined to be about $30 \mathrm{~K}$. Above approximately $50 \mathrm{~K}$ temperature dependency of the magnetic susceptibility $\chi(T)$ obeys the modified Curie-Weiss law:

$$
\chi(T)=\chi(0)+\frac{C}{(T-\theta)}
$$

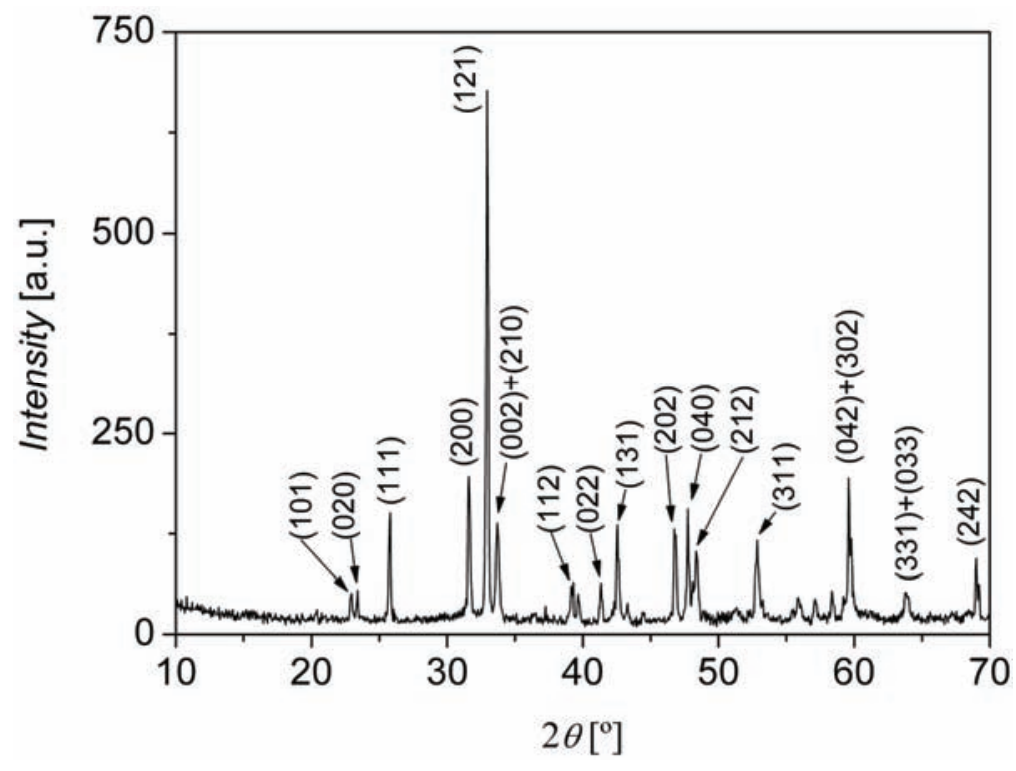

Figure 2. XRD Pattern of perovskite $\mathrm{YTiO}_{3}$ after annealing at $1150{ }^{\circ} \mathrm{C}$ for $12 \mathrm{~h}$ in vacuum.

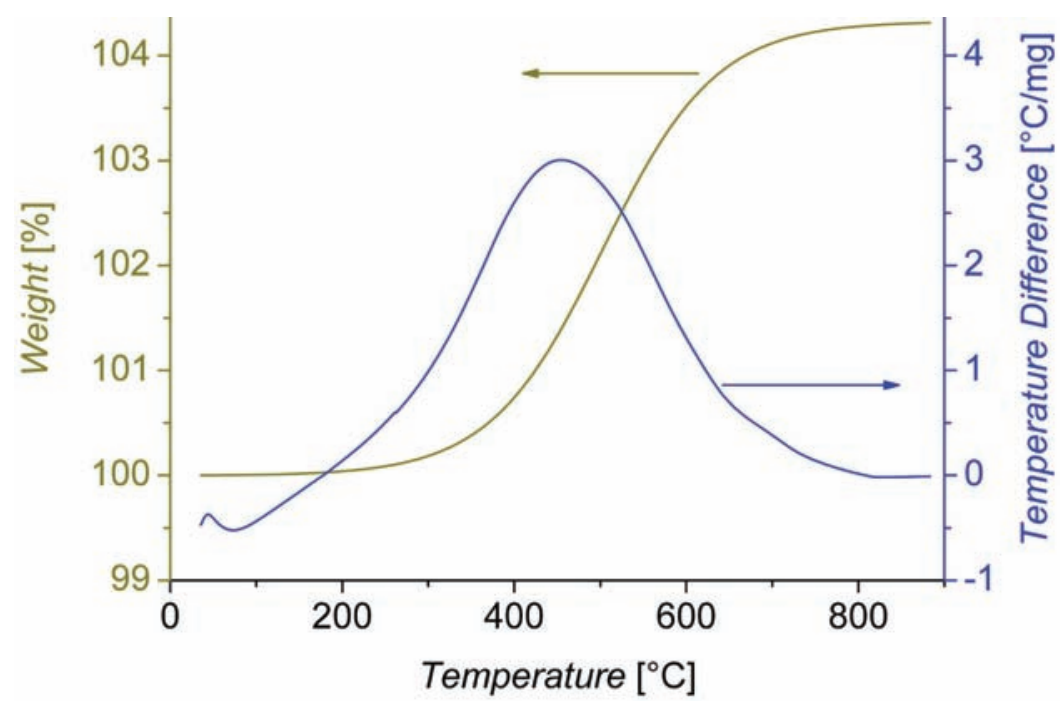

Figure 3. Simultaneous TGA/DTA measurements carried out up to $900{ }^{\circ} \mathrm{C}$ in the air atmosphere. 

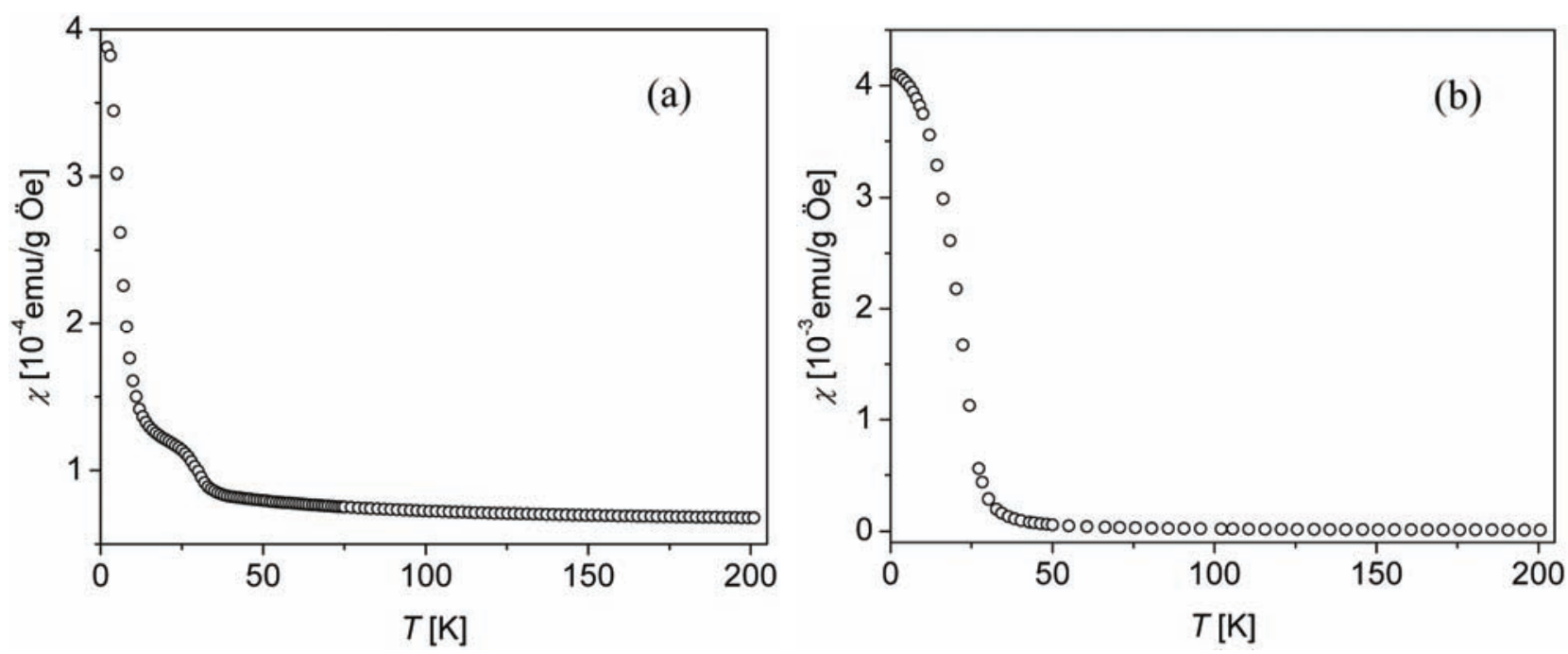

Figure 4. Temperature dependency of the magnetic susceptibility and its temperature derivative of a) as-milled and b) annealed samples in the temperature range of 2-200 K.

where $\chi(0)$ is temperature independent Pauli paramagnetic term, $C$ is Curie constant, $T$ is the absolute temperature and $\theta$ is the Curie temperature. The inverse magnetic susceptibility of both as-milled and annealed $\mathrm{YTiO}_{3}$ samples was fitted to the Eq. (1) within 100-200 $\mathrm{K}$ range, as shown in Figure 5 (susceptibility values depicted were corrected for Pauli paramagnetic contribution).

Fitting to the modified Curie-Weiss law (Eq. (1)) yields values for the Pauli paramagnetic term $\chi(0), \mathrm{Cu}$ rie constant $C$ and Curie-Weiss temperature $\theta$ (Table 1). By inspecting Table 1 , remarkable changes in both $\chi(0)$ and $\theta$ can be noticed. The Pauli paramagnetic term is an order of magnitude smaller for the annealed sample, while $\theta$ is almost of the same magnitude but with an opposite sign. In addition, the effective magnetic moment is about $4 \%$ larger for annealed sample.
Table 1. Magnetic parameters obtained by fitting Eq. (1) to measured susceptibility data in the 100-200 K range for as-milled and annealed $\mathrm{YTiO}_{3}$ samples; $M$ is the molecular mass and $\mu_{B}$ is the Bohr magneton; standard deviations are given in parentheses

\begin{tabular}{lcc}
\hline Parameter & As-prepared & Annealed \\
\hline$\chi(0) / 10^{-5} \mathrm{emu} \mathrm{g}^{-1} \mathrm{Oe}^{-1}$ & $6.232(7)$ & $0.446(9)$ \\
$C / 10^{-3} \mathrm{emu} \mathrm{g}^{-1} \mathrm{Oe}^{-1} \mathrm{~K}^{-1}$ & $1.22(2)$ & $1.31(2)$ \\
$\mu_{\mathrm{eff}} \approx \sqrt{8 C M} \mu_{\mathrm{B}}$ & $1.34(1)$ & $1.39(1)$ \\
$\theta / \mathrm{K}$ & $-20(1)$ & $26(1)$ \\
\hline
\end{tabular}

Isothermal magnetization of as-milled and annealed samples was measured as the function of applied field between -50 and $50 \mathrm{kOe}$ at the temperature of $24 \mathrm{~K}$, in the magnetically ordered state below $T_{\mathrm{C}}$ (Figure 6).

Hysteretic behavior of both samples is noticeable in the low fields region, while large differences in $M(H)$
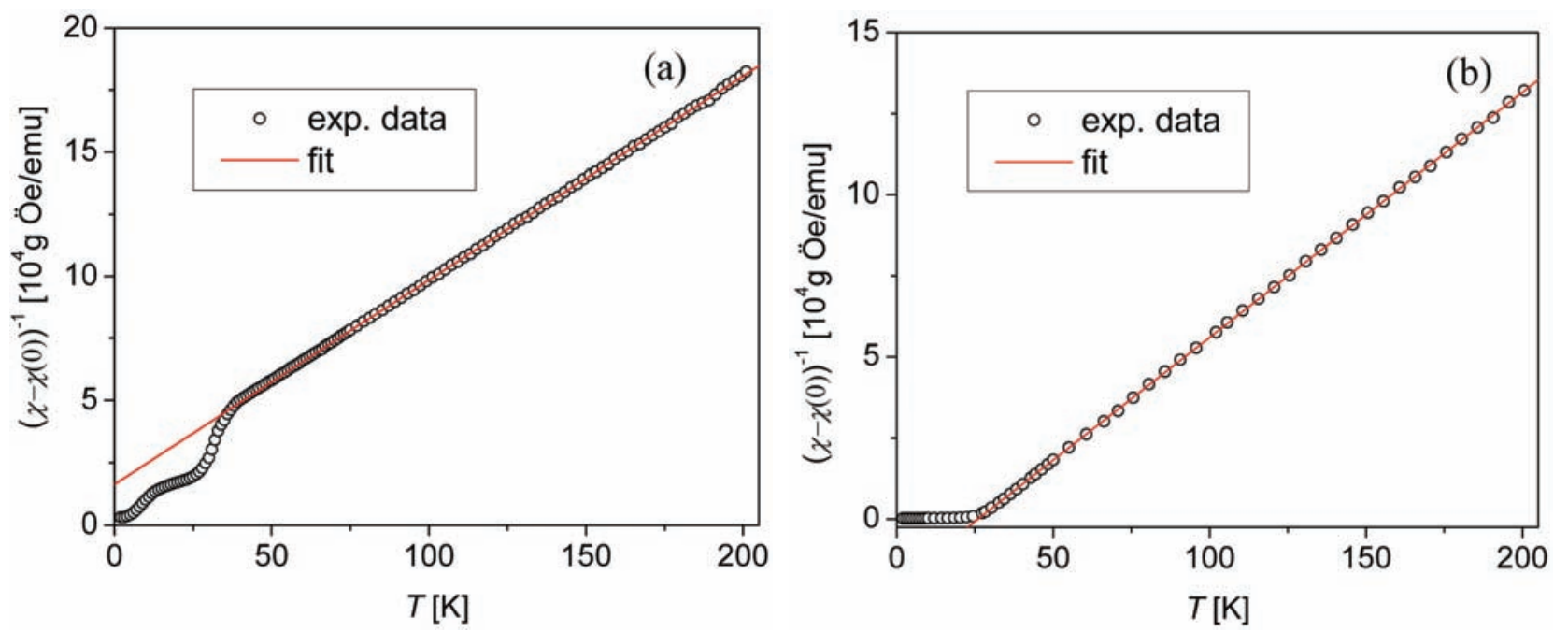

Figure 5. Inverse magnetic susceptibility corrected for Pauli temperature independent contribution fitted to the modified Curie-Weiss law at high temperatures (solid line) of a) as-milled and b) annealed samples. 

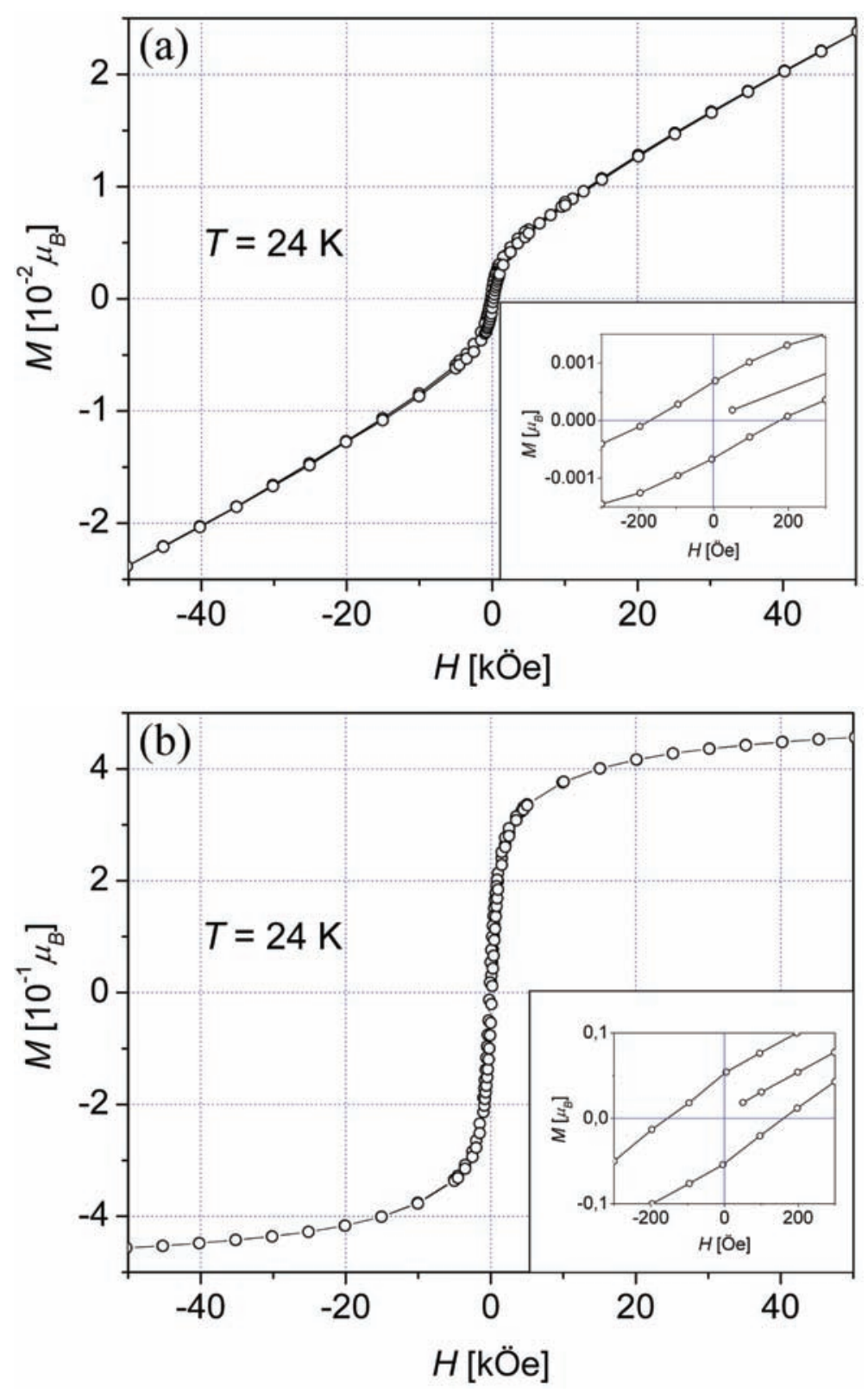

Figure 6. Magnetization, $M$, recorded in magnetic fields between -50 and $50 \mathrm{kOe}$ of a) as-milled and b) annealed samples at temperature of $24 K$.

dependency are observed in the higher fields region. The annealed sample shows behavior typical of soft ferromagnetics, with low coercivity value $H_{\mathrm{C}} \approx 170 \mathrm{Oe}$ and fast saturation of saturation magnetization $\mu_{\mathrm{S}}=$ $=0.45 \mu_{\mathrm{B}}$. In contrast, although the $H_{\mathrm{C}}$ value is almost the same, the as-milled sample displays absence of saturation with linear high field dependency.

Remarkable differences in both $\chi(T)$ and $M(H)$ behavior between as-milled and annealed sample can be understood as a result of different $\mathrm{TiO}_{6}$ octahedra distortions. Namely, $\mathrm{GdFeO}_{3}$-type distortion present in the annealed sample [3] is significantly perturbed in the asmilled sample due to the effect of vacancies and defects (i.e., various crystal imperfections) production by mechanochemical synthesis. In addition, small grain size (crystallites of $18 \mathrm{~nm}$ ) also significantly contributes to the crystal imperfections. These differences in $\mathrm{TiO}_{6}$ octahedra distortions alter both exchange interactions and $3 d$ electron bandwidth, thus affecting magnetic properties in the way that predominant AFM ordering of the as-milled sample changes to the ordering of the FM type in the annealed sample.

\section{CONCLUSION}

Successful synthesis of single-phase perovskite $\mathrm{YTiO}_{3}$ was accomplished for the first time by the mechanochemical method. This material belongs to a well-stu- 
died group $R \mathrm{TiO}_{3}$ in which $\mathrm{TiO}_{6}$ octahedra distortion is commonly controlled by either varying the $R$ species or concentration $x$ in solid solution $R_{1-x} R_{x}^{\prime} \mathrm{TiO}_{3}$ [13]. With this control, these systems exhibit an AFM-FM phase transition. In this work we have demonstrated that the same change of magnetic ordering can be accomplished on the single system by stabilizing the structure of the mechanochemically synthesized sample though annealing. The obtained results indicate that AFM-FM phase transition can be realized by establishing $\mathrm{GdFeO}_{3}$ type distortion in the annealed sample, which was intensively perturbed in the as-prepared sample. This additionally confirms that the magnetic properties of $R \mathrm{TiO}_{3}$ titanates are extremely sensitive to the magnitude and details of the lattice distortion [15].

\section{Acknowledgments}

This work was financially supported by the Serbian Ministry of Education and Science (Project Nos. 45015 and 45001).

\section{REFERENCES}

[1] M. Imada, A. Fujimori, Y. Tokura, Metal-insulator transitions, Rev. Mod. Phys. 70 (1998) 1039-1263.

[2] J.E. Greedan, The rare earth-titanium (III) perovskite oxides - An isostructural series with a remarkable variation in physical properties, J. Less-Common Met. 111 (1985) 335-435.

[3] D.A. MacLean, H.-N. Ng, J.E. Greedan, Crystal structures and crystal chemistry of the $\mathrm{RETiO}_{3}$ perovskites: $\mathrm{RE}=\mathrm{La}$, Nd, Sm, Gd, Y. J. Solid State Chem. 30 (1979) 35-44.

[4] Y. Okimoto, T. Katsufuji, Y. Okada, T. Arima, Y. Tokura, Optical spectra in $(\mathrm{La}, \mathrm{Y}) \mathrm{TiO}_{3}$ : Variation of Mott-Hubbard gap features with change of electron correlation and band filling, Phys. Rev., B 51 (1995) 9581-9588.
[5] J.P. Goral, J.E. Greedan, The magnetic structures of $\mathrm{LaTiO}_{3}$ and $\mathrm{CeTiO}_{3}$, J. Magn. Magn. Mater. 37 (1983) 315-321.

[6] M. Tsubota, F. Iga, T. Takabatake, N. Kikugawa, T. Suzuki, I. Oguro, H. Kawanaka, H. Bando, Low-field magnetic anisotropy in Mott-insulating ferromagnet $\mathrm{Y}_{1-x} \mathrm{Ca}_{x} \mathrm{TiO}_{3}(x \leq 0.1)$, Physica, B 281-282 (2000) 622-624.

[7] H.D. Zhou, J.B. Goodenough, Localized or itinerant $\mathrm{TiO}_{3}$ electrons in $\mathrm{RTiO}_{3}$ perovskites, J. Phys. Condens. Matter 17 (2005) 7395-7406.

[8] J.P. Goral, J.E. Greedan, D.A. MacLean, Magnetic behavior in the series $\mathrm{La}_{x} \mathrm{Y}_{1-x} \mathrm{TiO}_{3}$, J. Solid State Chem. 43 (1982) 244-250.

[9] A.C. Komarek, H. Roth, M. Cwik, W.-D. Stein, J. Baier, M. Kriener, F. Bourée, T. Lorenz, M. Braden, Magnetoelastic coupling in $\mathrm{RTiO}_{3}(\mathrm{R}=\mathrm{La}, \mathrm{Nd}, \mathrm{Sm}, \mathrm{Gd}, \mathrm{Y})$ investigated with diffraction techniques and thermal expansion measurements, Phys. Rev., B 75 (2007) 224402 (12 pages).

[10] T. Barudžija, A.A. Gusev, D. Jugović, M. Dramićanin, M. Zdujić, Č. Jovalekić, M. Mitrić, Structural and magnetic properties of mechanochemically synthesized nanocrystalline titanium monoxide, Hem. Ind. 66 (2012) 181$-186$.

[11] P.W. Selwood, Magnetochemistry, Interscience, London, 1956.

[12] H.P. Klug, L.E. Alexander, X-ray Diffraction Procedures, 2nd ed., Wiley, New York, 1974.

[13] M. Mochizuki, M. Imada, Orbital physics in the perovskite Ti oxides, New J. Phys. 6 (2004) 154.

[14] H.D. Zhou, J.B. Goodenough, Evidence for two electronic phases in $\mathrm{Y}_{1-x} \mathrm{La}_{x} \mathrm{TiO}_{3}$ from thermoelectric and magnetic susceptibility measurements, Phys. Rev., B 71 (2005) 184431.

[15] I.V. Solovyev, Superexchange interactions in orthorhombically distorted titanates $R \mathrm{TiO}_{3}(R=\mathrm{Y}, \mathrm{Gd}, \mathrm{Sm}$ and La), New J. Phys. 11 (2009) 093003. 


\section{IZVOD}

\section{STRUKTURNA I MAGNETNA SVOJSTVA MEHANOHEMIJSKI SINTETIZOVANOG ITRIJUM-TITANATA}

Tanja Barudžija ${ }^{1}$, Alexey A. Gusev ${ }^{2}$, Dragana Jugović ${ }^{3}$, Milena Marinović-Cincović ${ }^{1}$, Miroslav Dramićanin ${ }^{1}$, Miodrag Zdujić ${ }^{3}$, Čedomir Jovalekić ${ }^{4}$, Miodrag Mitrić ${ }^{1}$

${ }^{1}$ Univerzitet u Beogradu, Institut za nuklearne nauke „Vinča", Beograd, Srbija

${ }^{2}$ Institut za hemiju čvrstog stanja i mehanohemiju, Sibirski ogranak Ruske akademije nauka i umetnosti, Novosibirsk, Rusija

${ }^{3}$ Institut tehničkih nauka Srpske akademije nauka i umetnosti, Beograd, Srbija

${ }^{4}$ Univerzitet u Beogradu, Institut za multidisciplinarna istraživanja, Beograd, Srbija

(Naučni rad)

Nanostrukturni perovskit itrijum-titanat $\left(\mathrm{YTiO}_{3}\right)$ sa srednjom veličinom kristalita od $18 \mathrm{~nm}$ sintetizovan je, po prvi put, mehanohemijskim tretmanom smeše prahova komercijalnog $\mathrm{Y}_{2} \mathrm{O}_{3}$ i mehanohemijski sintetizovanog TiO u molarnom odnosu 0,5:1 u planetarnom mlinu u atmosferi argona. Posle $3 \mathrm{~h}$ mlevenja dobijen je itrijum titanat kao rezultat mehanohemijske reakcije. Termičkim tretmanom u vakuumu na $1150{ }^{\circ} \mathrm{C}, 12 \mathrm{~h}$, nanostrukturni $\mathrm{YTiO}_{3}$ transformisao se u dobro iskristalisani monofazni perovskit. Oba uzorka okarakterisana su rendgenskom strukturnom (XRD) i termogravimetrijskom (TGA/DTA) analizom, kao i magnetnim merenjem na SQUID magnetomeru.

Ključne reči: Itrijum-titanat • Mehanohemijska sinteza • Nanomaterijali • Strukturna svojstva • Magnetna svojstva 